Journal of Nuclear and Radiochemical Sciences, Vol. 6, No.3, pp. 205-210, 2005

\title{
Production and Chemistry of Transactinide Elements
}

\author{
Y. Nagame* \\ Advanced Science Research Center, Japan Atomic Energy Research Institute, Tokai, Ibaraki 319-1195, Japan
}

\author{
Received: July 31, 2005; In Final Form: September 30, 2005
}

Recent progress in production and chemistry of the transactinide elements, element 107 bohrium (Bh) and element 104 rutherfordium (Rf), is reviewed. First information on chemical properties of Bh was obtained in gas chromatographic experiments on an atom-at-a-time basis. Chemical separation and characterization of 6 atoms of ${ }^{267} \mathrm{Bh}$ produced in the bombardment of a ${ }^{249} \mathrm{Bk}$ target with ${ }^{22} \mathrm{Ne}$ beams are outlined. Aqueous chemistry of Rf being performed at JAERI (Japan Atomic Energy Research Institute) is briefly summarized. On-line anionexchange experiments in acidic solutions on ${ }^{261} \mathrm{Rf}$ produced in the ${ }^{248} \mathrm{Cm}\left({ }^{18} \mathrm{O}, 5 n\right)$ reaction were conducted with a rapid ion-exchange separation apparatus. Characteristic anion-exchange behavior of $\mathrm{Rf}$ is discussed.

\section{Introduction}

According to the actinide concept, ${ }^{1}$ the $5 f$ electron series ends with element 103 , lawrencium $(\mathrm{Lr})$, and a new $6 d$ electron transition series is predicted to begin with element 104 , rutherfordium (Rf). The elements with atomic numbers $Z \geq 104$ are called transactinide elements or recently called superheavy elements. ${ }^{2}$ The currently known transactinide elements, elements 104 through 112, are placed in the periodic table under their lighter homologues in the $5 d$ electron series, $\mathrm{Hf}$ to $\mathrm{Hg}$. Elements from 113 to 118 except for 117 synthesized by Oganessian et al. . $^{3,4}$ would be in the successive $7 p$ electron series (see Figure 1).

Studies of chemical properties of the transactinide elements offer unique opportunities to obtain information about trends in the periodic table of the elements at the limits of nuclear stability and to assess the magnitude of the influence of relativistic effects on chemical properties. From calculations of electron configurations of heavier elements, it is predicted that sudden changes in the structure of electron shells may appear due to relativistic effects which originate from the increasingly strong Coulomb field of a highly charged atomic nucleus. ${ }^{5}$ Therefore, it is expected that heavier elements show a drastic rearrangement of electrons in their atomic ground states, and as electron configurations are responsible for chemical behavior of elements, such relativistic effects can lead to surprising chemical properties. Increasing deviations from the periodicity of chemical properties based on extrapolation from lighter homologues in the periodic table are consequently predicted..$^{2,6-8}$ It would be no longer possible to deduce detailed chemical properties of the transactinide elements simply from the position of the periodic table.

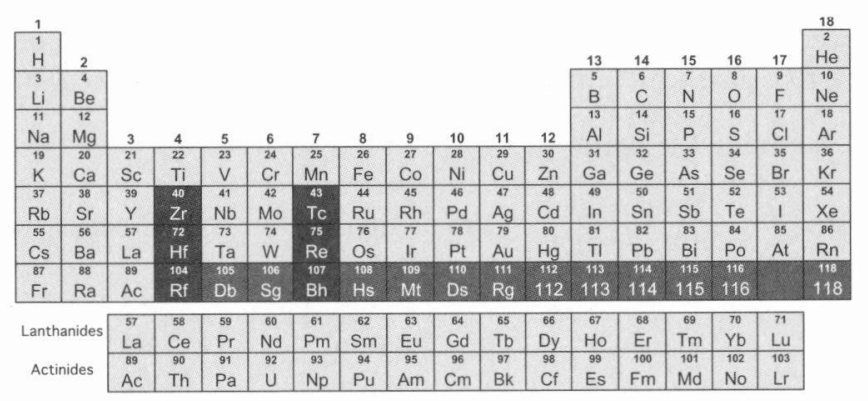

Figure 1. Periodic table of the elements.

*Corresponding author. E-mail: nagame.yuichiro@jaea.go.jp. FAX: +81-29-282-5927.
Chemical experiments with the transactinide elements are generally divided into the following 4 basic steps; i) synthesis of transactinide nuclides, ii) rapid transport of the synthesized nuclides to chemical separation apparatuses, iii) fast chemical isolation of a desired nuclide and preparation of a sample suitable for nuclear spectroscopy, and iv) detection of nuclides through their characteristic decay properties. Due to short halflives and low production rates of the transactinide nuclides, each atom produced decays before a new atom is synthesized. This means that any chemistry to be performed must be done on an "atom-at-a-time" basis. ${ }^{2,9,10}$ Thus, rapid and very efficient radiochemical procedures must be devised. Recent comprehensive reviews on the chemistry of the transactinide elements are found in References 2, 9, and 10.

The first successful chemical isolation and identification of Bh was accomplished in an experiment at the Philips cyclotron of PSI (Paul Sherrer Institute) by Eichler et al. ${ }^{11}$ The result clearly indicated that the volatile bohrium oxychloride complex behaved like a typical member of group 7 of the periodic table of the elements. From recent systematic studies of the anionexchange behavior of Rf, it was found that Rf is a member of the group 4 elements, ${ }^{12}$ although unexpected chemical behavior of Rf was observed in the fluoride complex formation. ${ }^{13}$

In this paper, chemical studies on gas chromatographic behavior of Bh at PSI and aqueous chemistry of Rf at JAERI are outlined.

\section{Production of Transactinide Elements}

Longer-lived transactinide nuclides required in chemical experiments exit in the neutron-rich region of the chart of nuclides and they are produced in so-called hot fusion reactions of such beams as ${ }^{18} \mathrm{O},{ }^{19} \mathrm{~F},{ }^{22} \mathrm{Ne}$, and ${ }^{26} \mathrm{Mg}$ with actinides targets of ${ }^{244} \mathrm{Pu},{ }^{248} \mathrm{Cm},{ }^{249} \mathrm{Bk}$, and so on. The produced transactinide nuclides must be identified by measurement of their decay or by that of their known daughter nuclei with unambiguous detection techniques.

A schematic representation of a typical experimental set-up for the production of transactinide nuclides is shown in Figure 2 where the target and recoil chamber for the production of ${ }^{261} \mathrm{Rf}$ at JAERI are depicted. A ${ }^{248} \mathrm{Cm}$ target of $610 \mu \mathrm{g} / \mathrm{cm}^{2}$ thickness prepared by electrodeposition of $\mathrm{Cm}\left(\mathrm{NO}_{3}\right)_{3}$ from isopropyl alcohol onto $2.4 \mathrm{mg} / \mathrm{cm}^{2}$ thick beryllium backing foil is bombarded by ${ }^{18} \mathrm{O}$ beams delivered from the JAERI tandem accelerator. The ${ }^{18} \mathrm{O}^{6+}$ beam passes through $2.0-\mathrm{mg} / \mathrm{cm}^{2}$ HAVAR entrance window foil, $0.09 \mathrm{mg} / \mathrm{cm}^{2} \mathrm{He}$ cooling gas 


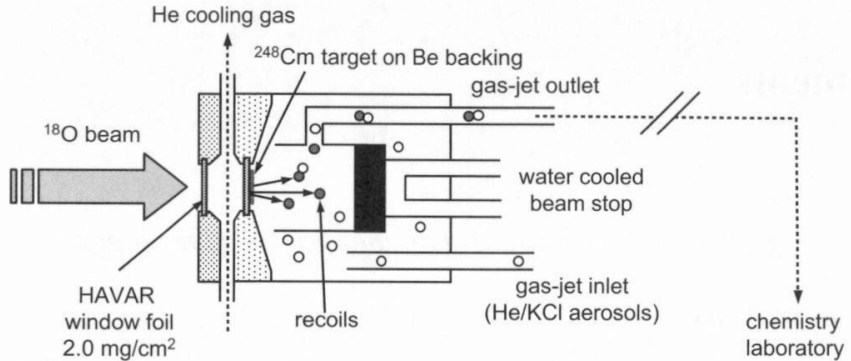

Figure 2. Schematic diagram of a target recoil chamber arrangement with a gas-jet system.

and the beryllium target backing, and it finally enters the ${ }^{248} \mathrm{Cm}$ target material. The reaction products recoiling out of the target are thermalized in a volume of $\mathrm{He}$ gas $(\approx 1$ bar $)$ which is loaded with potassium chloride $(\mathrm{KCl})$ aerosols generated by sublimation from the surface of $\mathrm{KCl}$ powder at $640{ }^{\circ} \mathrm{C}$. The products attached to the aerosols are swept out of the recoil chamber with the He gas flow $(2.0 \mathrm{~L} / \mathrm{min})$ and are transported through a Teflon-capillary (length $20 \mathrm{~m}$, inner diameter 2.0 $\mathrm{mm}$ ) by a $\mathrm{He} / \mathrm{KCl}$ gas-jet system to a chemistry laboratory.

The reactions and the expected production rates of the transactinide nuclides used for chemical studies are summarized in Table 1. Assuming the typical values of $800 \mu \mathrm{g} / \mathrm{cm}^{2}$ for the target thickness and the beam intensity of $3 \times 10^{12} \mathrm{~s}^{-1}$, one can anticipate the production rates, for example, to be 4 atoms per minute for $\mathrm{Rf}$ and a 1 atom per hour for $\mathrm{Bh}$.

\section{Gas-phase Chemistry of Element 107, Bohrium (Bh)}

Figure 3 shows the schematic of the experiment for the gasphase chemistry of Bh. ${ }^{11}$ A target of $670 \mu \mathrm{g} / \mathrm{cm}^{2}{ }^{249} \mathrm{Bk}$ covered with a layer of ${ }^{159} \mathrm{~Tb}\left(100 \mu \mathrm{g} / \mathrm{cm}^{2}\right)$ was bombarded for about 4 weeks with ${ }^{22} \mathrm{Ne}$ beams at a beam energy of $119 \mathrm{MeV}$ to produce ${ }^{267} \mathrm{Bh}$ in the reaction ${ }^{249} \mathrm{Bk}\left({ }^{22} \mathrm{Ne}, 4 n\right)$. Reaction products recoiling from the target were adsorbed onto the surface of carbon particles in He gas and were then continuously transported with the gas-jet system to the chemistry apparatus OLGA III (On-Line Gas chromatography Apparatus). ${ }^{20}$ The aerosol particles were collected on quartz wool inside the reaction oven kept at $1000{ }^{\circ} \mathrm{C}$. A mixture of $\mathrm{HCl}$ and $\mathrm{O}_{2}$ as reactive gas was introduced to form volatile oxychlorides. The chromatographic separation took place downstream in the isothermal temperature section of the quartz column (length $1.5 \mathrm{~m}$, inner diameter $1.5 \mathrm{~mm}$ ). The retention times of compounds in the column depend mainly on their adsorption interaction with the surface of the column at the isothermal temperature and on the carrier gas velocity. Thus, volatile molecules with a nuclear lifetime longer than the retention time passed through the column, and were subsequently attached to $\mathrm{CsCl}$ aerosol particles in $\mathrm{Ar}$ gas and transported to the detection system ROMA (ROtating wheel Multidetector Analyzer). The $\mathrm{CsCl}$ particles deposited in vacuum on thin foils mounted on the circumference of a stepwise

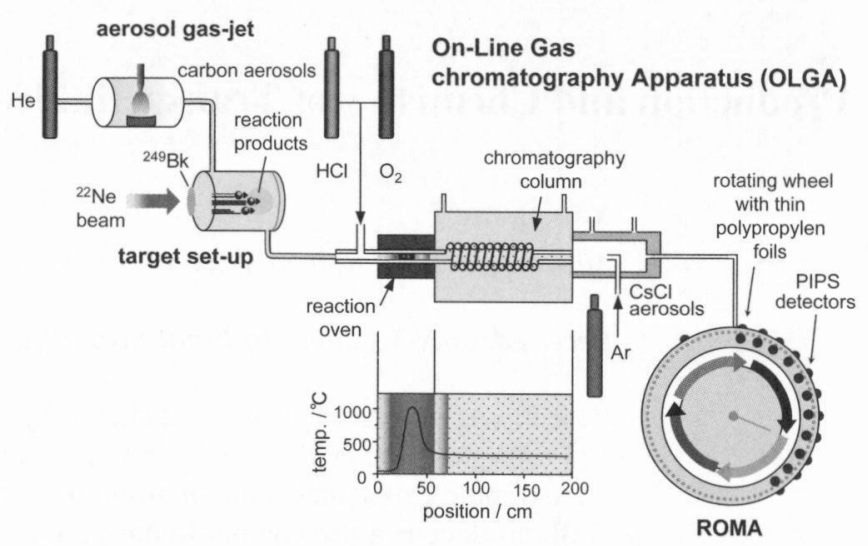

Figure 3. Schematic view of the Bh gas-chromatographic experiment. Courtesy of H. W. Gäggeler.

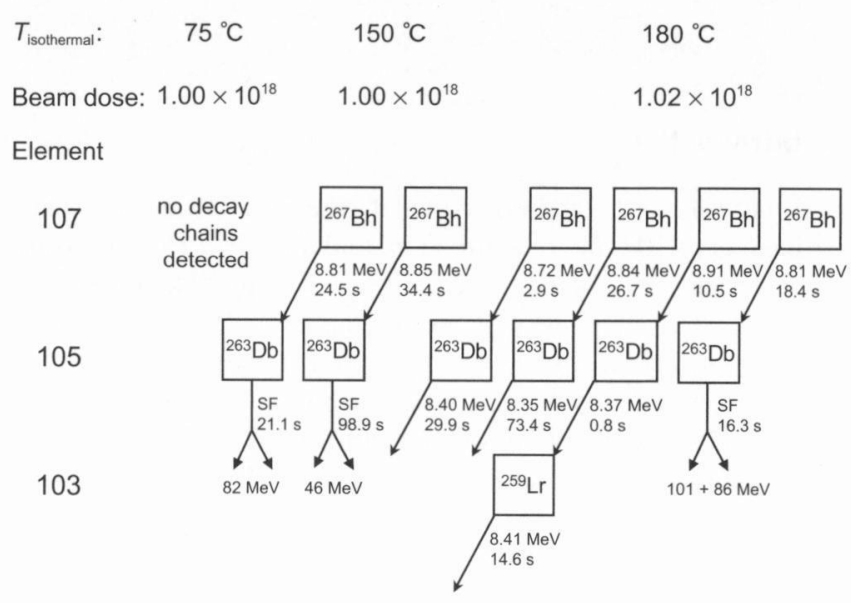

Figure 4. Decay chains attributed to the decay of ${ }^{267} \mathrm{Bh}$. The observed $\alpha$-particle and spontaneous fission decay energies and the lifetimes are given. Adapted from Reference 11.

rotating wheel. Every $10 \mathrm{~s}$ the collected samples were successively moved between a series of 12 pairs of PIPS (passivated ion-implanted planar silicon) detectors to measure the energy of $\alpha$-particles and spontaneous fission decay. Measurements were performed at three different isothermal temperatures. Rhenium186 was simultaneously produced in the reaction ${ }^{159} \mathrm{~Tb}\left({ }^{22} \mathrm{Ne}, 4 n\right)$, and was served as a yield monitor for the chemical separation process. The overall yield, including transportation of the products with the gas-jet system, chemical yields, and sample preparation in the detection system, was on the average about $16 \%$ for ${ }^{186}{ }^{18 e} .{ }^{11}$ The yield of ${ }^{186} \operatorname{Re}$ was measured with an HPGe $\gamma$-ray detector.

The nuclide ${ }^{267} \mathrm{Bh}$ decays by $\alpha$-particle emission to ${ }^{263} \mathrm{Db}$, an isotope of element 105 , which decays either by spontaneous fission or $\alpha$-particle emission to ${ }^{259} \mathrm{Lr}$. About 180,000 samples were measured throughout the experiment. As shown in Figure 4 , four genetically linked decay chains attributed to the decay of

TABLE 1: Typical Nuclides Used in Chemical Studies of the Transactinide Elements

\begin{tabular}{|c|c|c|c|c|c|c|}
\hline Atomic number & Nuclide & Half-life & Nuclear reaction & $\begin{array}{l}\text { Production } \\
\text { cross section }\end{array}$ & Production rate* & Reference \\
\hline 104 & ${ }^{261} \mathrm{Rf}$ & $78 \mathrm{~s}$ & ${ }^{248} \mathrm{Cm}\left({ }^{18} \mathrm{O}, 5 n\right)$ & $13 \mathrm{nb}$ & $4 \min ^{-1}$ & 14 \\
\hline 105 & ${ }^{262} \mathrm{Db}$ & $34 \mathrm{~s}$ & ${ }^{248} \mathrm{Cm}\left({ }^{19} \mathrm{~F}, 5 n\right)$ & $1.3 \mathrm{nb}$ & $0.5 \mathrm{~min}^{-1}$ & 14 \\
\hline 105 & ${ }^{262} \mathrm{Db}$ & $34 \mathrm{~s}$ & ${ }^{249} \mathrm{Bk}\left({ }^{18} \mathrm{O}, 5 n\right)$ & $6 \mathrm{nb}$ & $2 \min ^{-1}$ & 15 \\
\hline 106 & ${ }^{265} \mathrm{Sg}$ & $7.4 \mathrm{~s}$ & ${ }^{248} \mathrm{Cm}\left({ }^{22} \mathrm{Ne}, 5 n\right)$ & $0.24 \mathrm{nb}$ & $5 \mathrm{~h}^{-1}$ & 16 \\
\hline 107 & ${ }^{267} \mathrm{Bh}$ & $17 \mathrm{~s}$ & ${ }^{249} \mathrm{Bk}\left({ }^{22} \mathrm{Ne}, 4 n\right)$ & $60 \mathrm{pb}$ & $1 \mathrm{~h}^{-1}$ & 17 \\
\hline 108 & ${ }^{269} \mathrm{Hs}$ & $14 \mathrm{~s}$ & ${ }^{248} \mathrm{Cm}\left({ }^{26} \mathrm{Mg}, 5 n\right)$ & $6 \mathrm{pb}$ & $3 \mathrm{~d}^{-1}$ & 18 \\
\hline 112 & ${ }^{283} 112$ & $5.1 \mathrm{~min}$ & ${ }^{238} \mathrm{U}\left({ }^{48} \mathrm{Ca}, 3 n\right)$ & $3 \mathrm{pb}$ & $1.5 \mathrm{~d}^{-1}$ & 19 \\
\hline
\end{tabular}

*Assuming typical values of $800 \mu \mathrm{g} / \mathrm{cm}^{2}$ target thickness and $3 \times 10^{12} \mathrm{~s}^{-1}$ beam particles. Partly adapted from Reference 10 . 


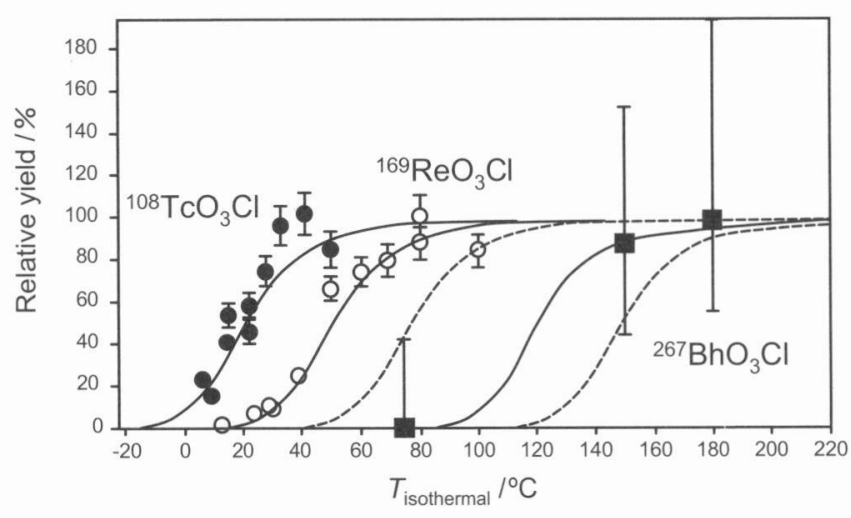

Figure 5. Isothermal gas chromatographic behavior of the oxychloride compounds of $\mathrm{Bh}, \mathrm{Tc}$, and $\mathrm{Re}$. The solid lines indicate the results of simulations with the microscopic model with the adsorption enthalpies given in the text. The dashed lines represent the calculated relative yield concerning the $68 \%$ confidence interval of the standard adsorption enthalpy of $\mathrm{BhO}_{3} \mathrm{Cl}$ from -66 to $-88 \mathrm{~kJ} / \mathrm{mol}$. Adapted from Reference 11.

${ }^{267} \mathrm{Bh}$ were detected at an isothermal temperature of $180{ }^{\circ} \mathrm{C}$, while at $150{ }^{\circ} \mathrm{C}, 2$ decay chains were observed and no decay chains were registered at $75^{\circ} \mathrm{C}$. A total of 6 atoms were detected during the experiment. ${ }^{11}$

Figure 5 shows the isothermal gas chromatographic behavior of $\mathrm{Bh}$ oxychloride, presumably $\mathrm{BhO}_{3} \mathrm{Cl}$, together with that of the group 7 metal oxychlorides in quartz columns. The data for $\mathrm{Tc}$ were obtained using a ${ }^{252} \mathrm{Cf}$ spontaneous fission source in a separate experiment. ${ }^{21}$ The relative yields of $\mathrm{BhO}_{3} \mathrm{Cl}$ after separation with the OLGA device are plotted as a function of isothermal temperatures and are compared with those of $\mathrm{TcO}_{3} \mathrm{Cl}$ and $\mathrm{ReO}_{3} \mathrm{Cl}$. The relative yield of $\mathrm{BhO}_{3} \mathrm{Cl}$ observed at $180{ }^{\circ} \mathrm{C}$ was normalized to $100 \%$. Although no $^{267} \mathrm{BhO}_{3} \mathrm{Cl}$ was observed at $75{ }^{\circ} \mathrm{C},{ }^{169} \mathrm{ReO}_{3} \mathrm{Cl}$ still passed the isothermal part of the column with about $80 \%$ of relative yield. From the gas adsorption chromatographic behavior of those molecules, the following enthalpies of adsorption on the column surface were deduced: $-\Delta H_{\mathrm{a}}{ }^{0}\left(\mathrm{TcO}_{3} \mathrm{Cl}\right)=51 \pm 3 \mathrm{~kJ} / \mathrm{mol},-\Delta H_{\mathrm{a}}{ }^{0}\left(\mathrm{ReO}_{3} \mathrm{Cl}\right)=61 \pm 3 \mathrm{~kJ} /$ $\mathrm{mol}$, and $-\Delta H_{\mathrm{a}}{ }^{0}\left(\mathrm{BhO}_{3} \mathrm{Cl}\right)=75_{-9}^{+6} \mathrm{~kJ} / \mathrm{mol}(68 \%$ confidence interval). ${ }^{11}$ The result clearly indicates that the sequence in volatility is $\mathrm{TcO}_{3} \mathrm{Cl}>\mathrm{ReO}_{3} \mathrm{Cl}>\mathrm{BhO}_{3} \mathrm{Cl}$. It is interesting to note that this sequence is consistent with predictions from relativistic densityfunctional calculations for group 7 oxychlorides $^{22}$ and also from classical extrapolations of periodic trends. ${ }^{11}$ This means that the volatile $\mathrm{BhO}_{3} \mathrm{Cl}$ behaves like a typical member of group 7 of the periodic table. ${ }^{11}$

\section{Aqueous Chemistry of Element 104, Rutherfordium (Rf)}

Ruthefordium-261 ( $\left.T_{1 / 2}=78 \mathrm{~s}\right)$ was produced at the JAERI tandem accelerator. The mixed target of ${ }^{248} \mathrm{Cm}\left(610 \mu \mathrm{g} / \mathrm{cm}^{2}\right.$ in thickness) and $\mathrm{Gd}\left(39.3 \%\right.$-enriched ${ }^{152} \mathrm{Gd}$ of $36 \mu \mathrm{g} / \mathrm{cm}^{2}$ in thickness) prepared by electrodeposition onto $2.4-\mathrm{mg} / \mathrm{cm}^{2}$ beryllium foil was used for simultaneous production of ${ }^{261} \mathrm{Rf}$ and 3.24-min ${ }^{169} \mathrm{Hf}$ via the ${ }^{248} \mathrm{Cm}\left({ }^{18} \mathrm{O}, 5 n\right)$ and $\mathrm{Gd}\left({ }^{18} \mathrm{O}, \mathrm{xn}\right)$ reactions, respectively. Hafnium-169 was served as a monitor of the on-line chemistry experiment. The reaction products recoiling out of the target were transported through a Teflon-capillary to the chemistry laboratory by the $\mathrm{He} / \mathrm{KCl}$ gas-jet system as mentioned in Section 2. To perform rapid and cyclic anion-exchange experiments with Rf, we employed an apparatus AIDA (Automated Ion-exchange separation apparatus coupled with the Detection system for Alpha-spectroscopy) $)^{12,23}$ that consisted of a modified ARCA (Automated Rapid Chemistry Apparatus), ${ }^{24}$ which was a miniaturized computer controlled liquid chromatography system, and an automated on-line $\alpha$-particle detection system. AIDA enables us to perform cyclic discontinuous column chromatographic separation of short-lived nuclides in

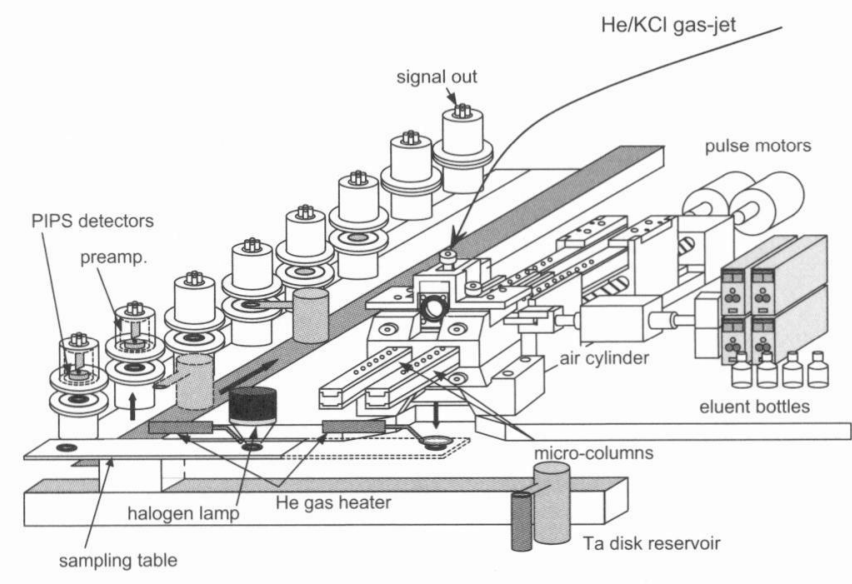

Figure 6. Schematic drawing of AIDA (Automated Ion-exchange separation apparatus coupled with the Detection system for Alpha spectroscopy). Adapted from Reference 23.

aqueous solutions and automated detection of $\alpha$-particles within a typical cycle of $1-2 \mathrm{~min}$. A schematic drawing of AIDA is given in Figure 6. There are two column magazines, each containing 20 micro columns. On-line anion-exchange experiments on $\mathrm{Rf}$ together with the group 4 elements $\mathrm{Zr}$ and $\mathrm{Hf}$ in acidic solutions, $\mathrm{HCl}, \mathrm{HNO}_{3}$, and $\mathrm{HF}$, were conducted with AIDA. The adsorption behavior of Rf as a function of the acid concentration was systematically studied. ${ }^{12,13}$ Quite recently, an elution curve of $\mathrm{Rf}$ has been obtained for the first time in anion-exchange chromatography on an atom-at-a-time basis. $^{25}$

In the following, the experimental procedures and the result on the anion-exchange behavior of $\mathrm{Rf}$ in $\mathrm{HCl}$ solution are summarized. The reaction products continuously transported through the $\mathrm{He} / \mathrm{KCl}$ gas-jet system deposited on a collection site of AIDA. After collection for $125 \mathrm{~s}$, the site was mechanically moved on the top of one of the micro columns, where the products were dissolved with $170 \mu \mathrm{L}$ of hot $\left(\approx 80{ }^{\circ} \mathrm{C}\right) 11.5 \mathrm{M}$ $\mathrm{HCl}$ and then fed onto the chromatographic column (length $7 \mathrm{~mm}$, inner diameter $1.6 \mathrm{~mm}$ ) filled with an anion-exchange resin MCl GEL CA08Y (particle size of about $20 \mu \mathrm{m}$ ) at a flow rate of $1.0 \mathrm{~mL} / \mathrm{min}$. The products were eluted with $290 \mu \mathrm{L}$ of $4.0-9.5 \mathrm{M} \mathrm{HCl}$ at a flow rate of $1.1 \mathrm{~mL} / \mathrm{min}$. The effluent was collected on a Ta disk as fraction 1 and then evaporated to dryness using hot $\mathrm{He}$ gas and a halogen heat lamp for $\alpha$-particle measurement. The remaining products in the column were eluted with $250 \mu \mathrm{L}$ of $4.0 \mathrm{M} \mathrm{HCl}$ at a flow rate of $1.1 \mathrm{~mL} / \mathrm{min}$. The effluent was collected on another Ta disk and evaporated to dryness as fraction 2. The pair of disks was automatically transported to the $\alpha$-spectroscopy station equipped with PIPS detectors. After the $\alpha$-particle measurement, $\gamma$-radiation of ${ }^{169} \mathrm{Hf}$ was monitored with $\mathrm{Ge}$ detectors to determine the elution behavior of $\mathrm{Hf}$ and its chemical yield. Each separation was accomplished within $20 \mathrm{~s}$ and the $\alpha$-particle measurement was initiated within $80 \mathrm{~s}$ after the collection of products at the AIDA collection site. The chemical yield of Hf, including collection and dissolution of the aerosols at the AIDA collection site, was approximately $60 \% .^{12}$

From 1893 cycles of the anion-exchange experiments, a total of $186 \alpha$ events from ${ }^{261} \mathrm{Rf}$ and its daughter ${ }^{257}$ No were registered, including $35 \alpha-\alpha$ correlation events. ${ }^{12}$ Figure 7 shows the adsorption behavior of $\mathrm{Rf}, \mathrm{Zr}$, and $\mathrm{Hf}$ as a function of $\mathrm{HCl}$ concentration. We measured the adsorption probability of $\mathrm{Zr}$ and $\mathrm{Hf}$ that were produced in the reactions $\mathrm{Ge}\left({ }^{18} \mathrm{O}, \mathrm{xn}\right)$ and $\mathrm{Gd}\left({ }^{18} \mathrm{O}, x n\right)$, respectively, under strictly identical conditions as those with $\mathrm{Rf}$ and $\mathrm{Hf}^{15}{ }^{15}$ The ordinate shows the adsorption probabilities of these elements, $100 A_{2} /\left(A_{1}+A_{2}\right)$, where $A_{1}$ and $A_{2}$ are the eluted radioactivities observed in fractions 1 and 2 , respectively. The adsorption behavior of $\mathrm{Rf}$ is quite similar to that of group 4 elements $\mathrm{Zr}$ and Hf. The adsorption of these 


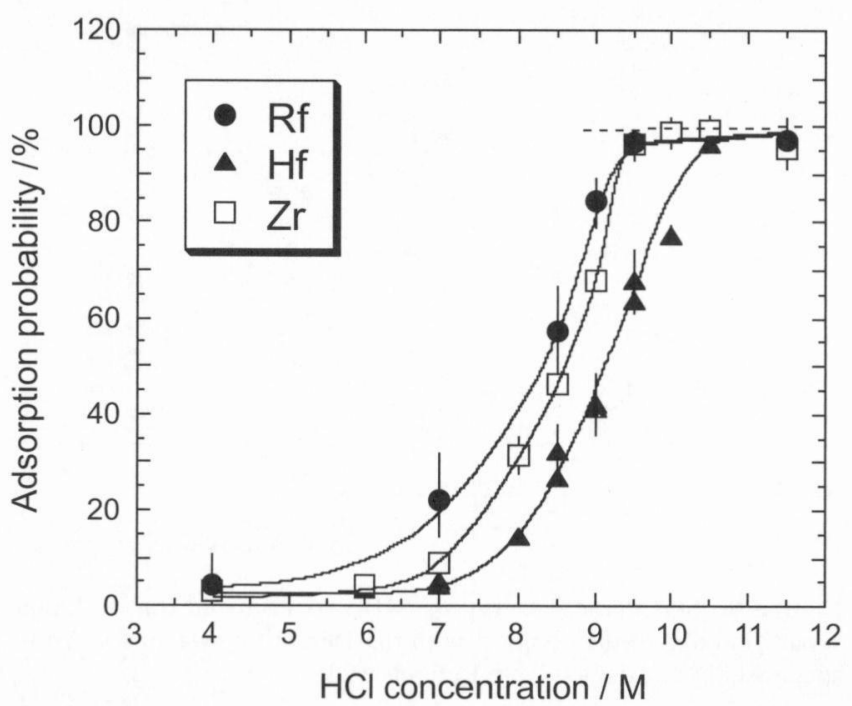

Figure 7. Adsorption probability of $\mathrm{Rf}, \mathrm{Zr}$, and $\mathrm{Hf}$ on the anionexchange resin $\mathrm{CA} 08 \mathrm{Y}$ as a function of $\mathrm{HCl}$ concentration. Adapted from Reference 12.

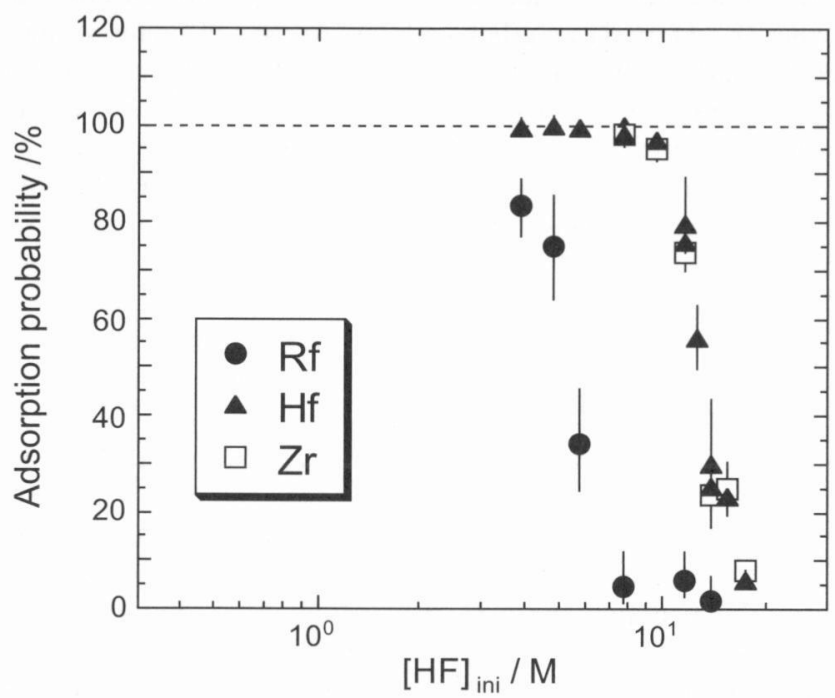

Figure 8. Adsorption behavior of $\mathrm{Rf}, \mathrm{Zr}$, and $\mathrm{Hf}$ on the anionexchange resin CA08Y as a function of the initial concentration of $\mathrm{HF},[\mathrm{HF}]_{\text {ini. }}$. Adapted from Reference 13.

elements rapidly increases with increasing $\mathrm{HCl}$ concentration higher than $7 \mathrm{M}$ : typical anion-exchange behavior of group 4 elements. This means that anionic chloride complexes of tetravalent $\mathrm{Rf}, \mathrm{Zr}$, and $\mathrm{Hf}$ are formed above $7 \mathrm{M}$ concentration of $\mathrm{HCl}^{12}$

Similar behavior of Rf was also probed with the anionexchange experiment in $8 \mathrm{M} \mathrm{HNO}_{3}$. From 217 experiments, a total of $20 \alpha$ events from ${ }^{261} \mathrm{Rf}$ and ${ }^{257}$ No were observed, including 5 time-correlated $\alpha$ pairs. It was found that $\mathrm{Rf}$ was eluted from the column with $8 \mathrm{M} \mathrm{HNO}_{3}$ as expected for a typical group 4 element. ${ }^{12}$ The above results definitely confirm that $\mathrm{Rf}$ is an element of group 4.

Unexpected anionic-exchange behavior of $\mathrm{Rf}$ in HF solution was observed. The experimental procedures with AIDA are basically the same as those described above and the details are given in Reference 13. From 4226 cycles of the anion-exchange experiments, a total of $266 \alpha$ events from ${ }^{261} \mathrm{Rf}$ and its daughter ${ }^{257} \mathrm{No}$ were registered, including 25 time-correlated $\alpha$ pairs of ${ }^{261} \mathrm{Rf}$ and ${ }^{257}$ No. Figure 8 shows a variation of the adsorption probability of $\mathrm{Rf}, \mathrm{Zr}$, and $\mathrm{Hf}$ as a function of the initial concentration of $\mathrm{HF},[\mathrm{HF}]_{\mathrm{ini}} \cdot{ }^{13}$ Adsorption behavior of $\mathrm{Zr}$ was obtained from the experiment using the Ge and Gd mixed target. ${ }^{13}$ The adsorption of $\mathrm{Zr}$ is fairly equal to that of $\mathrm{Hf}$ over a wide range of HF concentrations and steeply decreases with $[\mathrm{HF}]_{\text {ini }}$, while

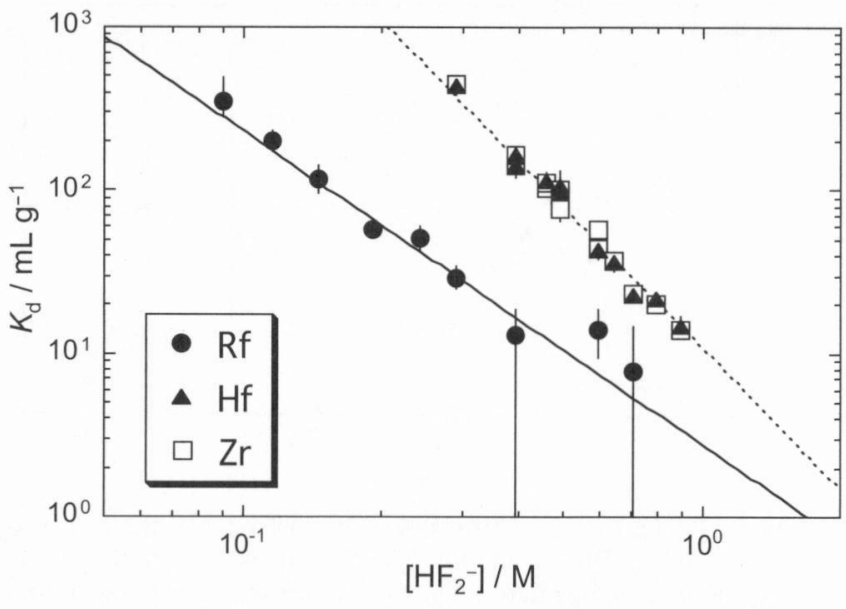

Figure 9. Distribution coefficients $\left(K_{\mathrm{d}}\right)$ for $\mathrm{Rf}, \mathrm{Zr}$, and $\mathrm{Hf}$ on the anion-exchange resin $\mathrm{CA} 08 \mathrm{Y}$ as a function of the concentration of $\mathrm{HF}_{2}{ }^{-}$. Adapted from References 13 and 23.

that of Rf decreases at much lower $[\mathrm{HF}]_{\text {ini }}$. The lower adsorption of $\mathrm{Rf}$ indicates that the fluoride complexation of $\mathrm{Rf}$ is weaker than those of $\mathrm{Zr}$ and $\mathrm{Hf}$.

The dissociation of HF is expressed as, ${ }^{26}$

$$
\begin{aligned}
& \mathrm{H}^{+}+\mathrm{F}^{-} \rightleftarrows \mathrm{HF} \\
& \mathrm{HF}+\mathrm{F}^{-} \rightleftarrows \mathrm{HF}_{2}^{-} .
\end{aligned}
$$

In terms of the dissociation constants $K_{1}=935 \mathrm{M}^{-1}$ for Equation (1) and $K_{2}=3.12 \mathrm{M}^{-1}$ for Equation (2), above $1 \mathrm{M}[\mathrm{HF}]_{\text {ini }}$, the concentration of anionic $\mathrm{HF}_{2}^{-}$is more than one order of magnitude higher than that of free $\mathrm{F}^{-}$. The $K_{\mathrm{d}}$ values for $\mathrm{Rf}, \mathrm{Zr}$, and $\mathrm{Hf}$ are plotted in Figure 9 as a function of the concentration of $\mathrm{HF}_{2}^{-},\left[\mathrm{HF}_{2}^{-}\right]$. The $K_{\mathrm{d}}$ values for $\mathrm{Rf}$ were deduced from the adsorption probability in Figure 8 by assuming that the reaction rates in the fluoride complexation and the anion-exchange process of $\mathrm{Rf}$ are as fast as those of the homologues $\mathrm{Zr}$ and $\mathrm{Hf}$ as described in Reference 13. The $K_{\mathrm{d}}$ values for $\mathrm{Zr}$ and $\mathrm{Hf}$ were from the on-line column chromatographic experiments with AIDA. A decrease of $K_{\mathrm{d}}$ values for these elements with $\left[\mathrm{HF}_{2}^{-}\right]$ is explained as the displacement of the metal complex from the binding sites of the resin with the counter ion $\mathrm{HF}_{2}{ }^{-}$as,

$$
\begin{aligned}
\mathrm{R}_{n}-\mathrm{MF}_{4+n}+n \cdot \mathrm{HF}_{2}^{-} \rightleftarrows & n \cdot \mathrm{R}_{-\mathrm{HF}_{2}+\mathrm{MF}_{4+n}{ }^{n-}} \\
& (\mathrm{M}=\mathrm{Rf}, \mathrm{Zr}, \text { and } \mathrm{Hf}),
\end{aligned}
$$

where $\mathrm{R}$ denotes the resin. As shown in Figure $9, K_{\mathrm{d}}$ values of these elements decrease linearly with increasing $\left[\mathrm{HF}_{2}^{-}\right]$in the $\log K_{\mathrm{d}}$ vs. $\log \left[\mathrm{HF}_{2}^{-}\right]$plot. It should be noted that the slopes for $\mathrm{Zr}$ and $\mathrm{Hf}$ are clearly -3 (dashed line), while that for $\mathrm{Rf}$ is -2 (solid line). This means that $\mathrm{Rf}$ is likely to be present as a hexafluoro complex, $\left[\mathrm{RfF}_{6}\right]^{2-}$ similar to the well known $\left[\mathrm{ZrF}_{6}\right]^{2-}$ and $\left[\mathrm{HfF}_{6}\right]^{2-}$ at lower $[\mathrm{HF}]_{\text {ini }}$, while $\mathrm{Zr}$ and $\mathrm{Hf}$ are likely to be present in the form of heptafluoro complexes, $\left[\mathrm{ZrF}_{7}\right]^{3-}$ and $\left[\mathrm{HfF}_{7}\right]^{3-}$ as suggested in References 27 and 28. Activity coefficients of the chemical species involved are not available for higher concentration of HF, and the definite identification of the anionic fluoride complexes is still an open question.

Relativistic density-functional calculations of the electronic structures of hexafluoro complexes $\left(\left[\mathrm{MF}_{6}\right]^{2-}, \mathrm{M}=\mathrm{Rf}, \mathrm{Zr}\right.$ and Hf) have been performed to evaluate the stability of the complexes. The results of calculations that the sequence in the overlap population between the valence $d$ orbitals of $\mathrm{M}^{4+}$ and the valence orbitals of $\mathrm{F}^{-}$is $\mathrm{Zr} \approx \mathrm{Hf}>\mathrm{Rf}$ suggest that the $\mathrm{Rf}$ complex is less stable than those of $\mathrm{Zr}$ and $\mathrm{Hf}$ in the $\left[\mathrm{MF}_{6}\right]^{2-}$ structure. $^{29}$ Although the calculations qualitatively agree with the experimental results, further theoretical approaches are 
needed to quantitatively understand the present interesting results.

\section{Summary}

Chemical studies of Bh and Rf on an atom-at-a-time basis gave the following outcomes. Bohrium behaves like a typical member of group 7 of the periodic table and forms a volatile oxychloride, presumably $\mathrm{BhO}_{3} \mathrm{Cl}$, which is less volatile than those of the lighter homologues Tc and Re. The adsorption behavior of $\mathrm{Rf}$ in anion-exchange chromatography is quite similar to that of $\mathrm{Zr}$ and $\mathrm{Hf}$ in $\mathrm{HNO}_{3}$ and $\mathrm{HCl}$ solutions, clearly confirming that $\mathrm{Rf}$ is an element of group 4. On the other hand, a large difference was observed in the adsorption behavior of $\mathrm{Rf}$ on the anion-exchange resin in HF solution, i.e., the fluoride complexation of $\mathrm{Rf}$ is much weaker than those of the homologues.

From artistic chemical studies of the transactinide elements performed so far including the results described here, one can place the elements 104 through 108 in their respective group of the periodic table, i.e., $\mathrm{Rf}, \mathrm{Db}, \mathrm{Sg}, \mathrm{Bh}$, and $\mathrm{Hs}$ in group 4, 5, 6, 7 , and 8, respectively. ${ }^{2,7,30}$ However, as observed in the fluoride complexation of Rf, unexpected chemical behavior partly caused by relativistic effects would appear in chemical properties of the transactinide elements. To enhance the understanding on chemical properties of the transactinide elements, more systematic experiments as well as quantitative theoretical calculations are required.

Acknowledgment. The author would like to thank his group members in JAERI and all colleagues from RIKEN, Osaka, Niigata, Kanazawa, Tokyo, Tsukuba, Shizuoka, Tokushima, Darmstadt, and Mainz in the Rf experiment at JAERI. The chemical studies on Rf are supported in part by the JAERIUniversity Collaboration Research Program and by the Program on the Scientific Cooperation between JAERI and GSI in Research and Development in the Field of Ion Beam Application. He is grateful to H. W. Gäggeler for providing him valuable information on the chemical studies of Bh.

\section{References}

(1) G. T. Seaborg, Chem. Eng. News 23, 2190 (1945).

(2) The Chemistry of Superheavy Elements, ed. M. Schädel, Kluwer Academic Publishers, Dordrecht, 2003.

(3) Yu. Ts. Oganessian, V. K. Utyonkov, Yu. V. Lobanov, F. Sh. Abdullin, A. N. Polyakov, I. V. Shirokovsky, Yu. S. Tsyganov, G. G. Gulbekian, S. L. Bogomolov, B. N. Gikal, A. N. Mezentsev, S. Iliev, V. G. Subbotin, A. M. Sukhov, A. A. Voinov, G. V. Buklanov, K. Subotic, V. I. Zagrebaev, M. G. Itkis, J. B. Patin, K. J. Moody, J. F. Wild, M. A. Stoyer, N. J. Stoyer, D. A. Shaughnessy, J. M. Kenneally, and R. W. Lougheed, Nucl. Phys. A734, 109 (2004).

(4) Yu. Ts. Oganessian, V. K. Utyonkov, Yu. V. Lobanov, F. Sh. Abdullin, A. N. Polyakov, I. V. Shirokovsky, Yu. S. Tsyganov, G. G. Gulbekian, S. L. Bogomolov, A. N. Mezentsev, S. Iliev, V. G. Subbotin, A. M. Sukhov, A. A. Voinov, G. V. Buklanov, K. Subotic, V. I. Zagrebaev, M. G. Itkis, J. B. Patin, K. J. Moody, J. F. Wild, M. A. Stoyer, N. J. Stoyer, D. A. Shaughnessy, J. M. Kenneally, and R. W. Lougheed, Phys. Rev. C 69, 021601 (2004).

(5) B. Fricke and W. Greiner, Phys. Lett. 30B, 317 (1969).

(6) P. Pyykkö, Chem. Rev. 88, 563 (1988).

(7) V. Pershina, Chem. Rev. 96, 1977 (1996).

(8) P. Schwerdtfeger and M. Seth, Encyclopedia of Computational Chemistry, Vol. 4, eds. P. von R. Schleyer et al., Wily, New York, 1998, p. 2480.'

(9) J. V. Kratz, Chemistry of Transactinides. In: Handbook of Nuclear Chemistry, Vol. 2, Elements and Isotopes, eds. A.
Vértes, S. Nagy, Z. Klencsár, Kluwer Academic Publishers, Dordrecht, 2003, p. 323.

(10) M. Schädel, J. Nucl. Radiochem. Sci. 3, 113 (2002).

(11) R. Eichler, W. Brüchle, R. Dressler, Ch. E. Düllmann, B. Eichler, H. W. Gäggeler, K. E. Gregorich, D. C. Hoffman, S. Hübener, D. T. Jost, U. W. Kirbach, C. A. Laue, V. M. Lavanchy, H. Nitsche, J. B. Patin, D. Pluguet, M. Schädel, D. A. Shaughnessy, D. A. Strellis, S. Taut, L. Tobler, Y. S. Tsyganov, A. Türler, A. Vahle, P. A. Wilk, and A. B. Yakushev, Nature 407, 63 (2000).

(12) H. Haba, K. Tsukada, M. Asai, S. Goto, A. Toyoshima, I. Nishinaka, K. Akiyama, M. Hirata, S. Ichikawa, Y. Nagame, Y. Shoji, M. Shigekawa, T. Koike, M. Iwasaki, A. Shinohara, T. Kaneko, T. Maruyama, S. Ono, H. Kudo, Y. Oura, K. Sueki, H. Nakahara, M. Sakama, A. Yokoyama, J. V. Kratz, M. Schädel, and W. Brüchle, J. Nucl. Radiochem. Sci. 3, 143 (2002).

(13) H. Haba, K. Tsukada, M. Asai, A. Toyoshima, K. Akiyama, I. Nishinaka, M. Hirata, T. Yaita, S. Ichikawa, Y. Nagame, K. Yasuda, Y. Miyamoto, T. Kaneko, S. Goto, S. Ono, T. Hirai, H. Kudo, M. Shigekawa, A. Shinohara, Y. Oura, H. Nakahara, K. Sueki, H. Kikunaga, N. Kinoshita, N. Tsuruga, A. Yokoyama, M. Sakama, S. Enomoto, M. Schädel, W. Brüchle, and J. V. Kratz, J. Am. Chem. Soc. 126, 5219 (2004).

(14) Y. Nagame, M. Asai, H. Haba, S. Goto, K. Tsukada, I. Nishinaka, K. Nishio, S. Ichikawa, A. Toyoshima, K. Akiyama, H. Nakahara, M. Sakama, M. Schädel, J. V. Kratz, H. W. Gäggeler, and A. Türler, J. Nucl. Radiochem. Sci. 3, 85 (2002).

(15) J. V. Kratz, M. K. Gober, H. P. Zimmermann, M. Schädel, W. Brüchle, E. Shimpf, K. E. Gregorich, A. Türler, N. J. Hannink, K. R. Czerwinski, B. Kadkhodayan, D. M. Lee, M. J. Nurmia, D. C. Hoffman, H. W. Gäggeler, D. Jost, J. Kovacs, U. W. Scherer, and A. Weber, Phys. Rev. C 45, 1064 (1992).

(16) A. Türler, R. Dressler, B. Eichler, H. W. Gäggeler, D. T. Jost, M. Schädel, W. Brüchle, K. E. Gregorich, N. Trautmann, and S. Taut, Phys. Rev. C 57, 1648 (1998).

(17) P. A. Wilk, K. E. Gregorich, A. Türler, C. A. Laue, R. Eichler, V. Ninov, J. L. Adams, U. W. Kirbach, M. R. Lane, D. M. Lee, J. B. Patin, D. A. Shaughnessy, D. A. Strellis, H. Nitsche, and D. C. Hoffman, Phys. Rev. Lett. 85, 2697 (2000).

(18) A. Türler, Ch. E. Düllmann, H. W. Gäggeler, U. W. Kirbach, A. B. Yakushev, M. Schädel, W. Brüchle, R. Dressler, K. Eberhardt, B. Eichler, R. Eichler, T. N. Ginter, F. Glaus, K. E. Gregorich, D. C. Hoffman, E. Jäger, D. T. Jost, D. M. Lee, H. Nitsche, J. B. Patin, V. Pershina, D. Piguet, Z. Qin, B. Schausten, E. Shimpf, H.-J. Schött, S. Soverna, R. Sudowe, P. Thörle, S. N. Timokhin, N. Trautmann, A. Vahle, G. Wirth, and P. M. Zielinski, Eur. Phys. J. A 17, 505 (2003).

(19) Yu. Ts. Oganessian, A. V. Yeremin, G. G. Gulbekian, S. L. Bogomolov, V. I. Chepigin, B. N. Gikal, V. A. Gorshkov, M. G. Itkis, A. P. Kabachenko, V. B. Kutner, A. Yu. Lavrentev, O. N. Malyshev, A. G. Popeko, J. Rohác, R. N. Sagaidak, S. Hofmann, G. Münzenberg, M. Veselsky, S. Saro, N. Iwase, and K. Morita, Eur. Phys. J. A 5, 63 (1999); Yu. Ts. Oganessian, A. V. Yeremin, A. G. Popeko, O. N. Malyshev, A. V. Belozerov, G. V. Buklanov, M. L. Chelnokov, V. I. Chepigin, V. A. Gorshkov, S. Hofmann, M. G. Itkis, A. P. Kabachenko, B. Kindler, G. Münzenberg, R. N. Sagaidak, S. Saro, H.-J. Schött, B. Streicher, A. V. Shutov, A. I. Svirikhin, and G. K. Vostokin, Eur. Phys. J. A 19, 3 (2004).

(20) H. W. Gäggeler, D. T. Jost, U. Baltensperger, A. Weber, J. Kovacs, D. Vermeulen, and A. Türler, Nucl. Instr. Methods A 309, 201 (1991).

(21) R. Eichler, B. Eichler, H. W. Gäggeler, D. T. Jost, D. 
Piguet, and A. Türler, Radiochim. Acta 88, 87 (2000).

(22) V. Pershina and T. Bastug, J. Chem. Phys. 113, 1441 (2000).

(23) Y. Nagame, K. Tsukada, M. Asai, A. Toyoshima, K. Akiyama, Y. Ishii, T. Kaneko-Sato, M. Hirata, I. Nishinaka, S. Ichikawa, H. Haba, S. Enomoto, K. Matsuo, D. Saika, Y. Kitamoto, H. Hasegawa, Y. Tani, W. Sato, A. Shinohara, M. Ito, J. Saito, S. Goto, H. Kudo, H. Kikunaga, N. Kinoshita, A. Yokoyama, K. Sueki, Y. Oura, H. Nakahara, M. Sakama, M. Schädel, W. Brüchle, and J. V. Kratz, Radiochim. Acta 93, 519 (2005).

(24) M. Schädel, W. Brüchle, E. Jäger, E. Schimpf, J. V. Kratz, U. W. Scherer, H. P. Zimmermann, Radiochim. Acta 48, 171 (1989).

(25) A. Toyoshima, H. Haba, K. Tsukada, M. Asai, K. Akiyama, I. Nishinaka, Y. Nagame, D. Saika, K. Matsuo, W. Sato, A. Shinohara, H. Ishizu, M. Ito, J. Saito, S. Goto, H. Kudo, H. Kikunaga, N. Kinoshita, C. Kato, A. Yokoyama, and K. Sueki, J. Nucl. Radiochem. Sci. 5, 45 (2004).
(26) P. M. Plaisance, R. Guillaumont, Radiochim. Acta 12, 32 (1969).

(27) J. I. Kim, H. Lagally, H.-J. Born, Anal. Chim. Acta 64, 29 (1973).

(28) J. Korkisch, Handbook of Ion Exchange Resins: Their Application to Inorganic and Analytical Chemistry, CRC Press, Boca Raton, FL, 1989.

(29) M. Hirata, private communication.

(30) Ch. E. Düllmann, W. Brüchle, R. Dressler, K. Eberhardt, B. Eichler, R. Eichler, H. W. Gäggeler, T. N. Ginter, F. Glaus, K. E. Gregorich, D. C. Hoffman, E. Jäger, D. T. Jost, U. W. Kirbach, D. M. Lee, H. Nitsche, J. B. Patin, V. Pershina, D. Piguet, Z. Qin, M. Schädel, B. Schausten, E. Schimpf, H.-J. Schött, S. Soverna, R. Sudowe, P. Thörle, S. N. Timokhin, N. Trautmann, A. Türler, A. Vahle, G. Wirth, A. B. Yakushev, and P. M. Zielinski, Nature, 418, 859 (2002). 